\title{
Characterisation of Mass Transfer in Frontal Nanofiltration Equipment and Development of a Simple Correlation
}

\author{
Darren L. Oatley-Radcliffe*, Steffan R. Williams, Christopher Lee and Paul M. Williams
}

Centre for Water Advanced Technologies and Environmental Research (CWATER), College of Engineering, Swansea University, Singleton Park, Swansea SA2 8PP, UK

\begin{abstract}
This aim of this work was to investigate the effects of mass transfer in three commercially available frontal nanofiltration systems (Amicon, Sterlitech and Membranology) using the rejection of uncharged poly ethylene glycol (molecular weight 3400) at different pressures and stirrer speeds using a 4000 MWCO membrane. The real rejection was calculated from the observed rejection using the infinite rejection method and a comparison was made between experimentally obtained mass transfer coefficients and those obtained from commonly used ultrafiltration theory. A new mass transfer correlation was proposed that is more appropriate to account for the increased mass transfer effects observed with the larger pressures of nanofiltration. This new correlation is defined as $N_{S h}=\varphi\left(N_{R e}\right)^{n}\left(N_{S c}\right)^{0.33}\left(1+\left(\frac{J v}{\omega r}\right)^{x}\right)$
\end{abstract} is only a minor modification to existing theory and has an accuracy suitable for engineering design purposes.

Keywords: Mass transfer, Concentration polarisation, Equipment characterisation, Frontal filtration, Nanofiltration.

\section{INTRODUCTION}

The last two decades have seen membrane technology develop enormously. Membrane applications are continuing to expand rapidly, in particular for the food, biotechnology and water treatment industries. This expansion is predominantly due to the ambient process conditions and lower operating costs of the membrane process when compared to more traditional separation technologies [1]. However, the growth of the technology has been somewhat impeded due to flux decline with time [2,3] and a lack of fundamental understanding for prediction and modelling which inhibits rapid scale-up [4]. The optimal design of a membrane process should ensure maximum permeate flux while obtaining maximum solute rejection, with minimal capital and operational costs [5]. Therefore, in order to design an optimal commercial scale membrane process, development and understanding from laboratory and pilot scale studies are regarded as imperative.

The performance of membrane applications is normally evaluated using small scale laboratory test equipment over a range of operating conditions such as pressure, mixing rate (stirrer speed or cross-flow rate) and feed composition. Solute rejection/retention, concentration polarisation and hydrodynamic profile are all significant considerations and are not always interlinked [6]. Frontal filtration (sometimes referred to as dead-end filtration) in laboratory scale cylindrical

*Address correspondence to this author at the Centre for Water Advanced Technologies and Environmental Research (CWATER), College of Engineering, Swansea University, Singleton Park, Swansea SA2 8PP, UK; Tel: + 44 (0)1792 606 668; E-mail: d.I.oatley@swansea.ac.uk stirred cells is used extensively for the testing of all types of membrane applications (MF, UF, NF, RO). The relatively simplistic equipment needed and excellent control of the separation conditions make these laboratory stirred cells ideal for practical and experimental purposes, although correct data interpretation requires accurate knowledge of the interfacial events and transport phenomena occurring at the membrane surface [7]

Permeate flux decline is an important phenomena inevitably associated with membrane processes. The initial rapid decline is attributed to concentration polarisation (solute build-up) while the slower more gradual decline is attributed to physical fouling (microbial adhesion, gel layer formation and solute adhesion) of the membrane surface [8]. Traditionally the emphasis is on the study of long-term flux decline mechanisms, a topic reviewed by Guo et al. [9]. However, concentration polarisation is noted as a fouling mechanism [10]; therefore a fundamental understanding of the dynamics of concentration polarisation can assist in the understanding and prevention of cake formation [8] and a decline in process performance [11].

Concentration polarisation (CP) is an important factor that influences the performance of membrane separation processes [12] mainly by limiting the flux due to increased concentration at the membrane surface [13]. The increased concentration at the membrane surface leads to an equilibrium shift and back diffusion of the permeating solute into the bulk feed solution. This increased surface concentration 
also leads to a lower flux (solvent transport through the membrane) as a result of the increased osmotic pressure generated. Both phenomena reduce the overall separation efficiency. These phenomena eventually attain a steady state and hence generate a concentration gradient at the membrane surface [14]. The extent of concentration polarisation depends on several factors which are a combination of solute properties, membrane properties and hydrodynamics, namely $[15,16]$ :

- Competition between solute convection towards the membrane and diffusion away from the membrane,

- the fraction of solute rejected by the membrane,

- the flow regime within the module (whether laminar or turbulent),

- $\quad$ the module geometry and

- $\quad$ the feed velocity tangential to the membrane.

Characterisation of membrane systems is often performed by studying the rejection of a tracer solute particularly for the determination of membrane MWCO [17]. Understanding the mass transfer characteristics of the membrane equipment being used is essential in the accurate determination of membrane rejection properties as the difference between observed and real rejection may be significant. However, once mass transfer is accounted for the real rejection in all equipment will be similar and provides a methodology for scale up between small flat sheet studies to industrial modules.

The objective of this study was to investigate the concentration polarisation and mass transfer effects occurring in three commercially available frontal filtration membrane cells (Amicon, Sterlitech and Membranology) through the analysis of rejection data for poly ethylene glycol (PEG), an uncharged solute.

\section{MATERIALS \& METHODS}

\section{Relevant Theory}

The experimental rejection characteristics of a membrane are typically defined by observed rejection [18]:

$R_{o b s}=1-\frac{C_{P}}{C_{F}}$ where $C_{P}$ and $C_{F}$ are the concentrations of the permeate and feed respectively. In reality, due to concentration polarisation this definition of rejection is not accurate because the concentration at the membrane surface, $\mathrm{C}_{\mathrm{W}}$ is higher than that of the bulk feed concentration, $C_{f}$. The real rejection of the solute, $R$, which is always equal to or greater than $R_{o b s}$ is defined as:

$R_{\text {real }}=1-\frac{C_{P}}{C_{w}}$

The concentration at the wall, $\mathrm{C}_{\mathrm{W}}$, is extremely difficult to measure directly and therefore is normally calculated indirectly using a suitable model for concentration polarisation [19]. The approach to concentration polarisation taken in this study is that of the infinite rejection method first reported by Nakao and Kimura [20] and given as:

$\exp \left(\frac{J_{v}}{k}\right)=\frac{C_{w}-C_{p}}{C_{f}-C_{p}}$

where $J_{v}$ is volumetric flux through the membrane and $k$ is the mass transfer coefficient in the polarised boundary layer, defined as:

$k=\frac{D_{e f f}, \infty}{\delta}$

and $D_{e f f}, \infty$ is the effective diffusion coefficient at infinite dilution and $\delta$ is the thickness of the concentration polarisation layer.

The mass transfer coefficient may be determined experimentally by the substitution of equation (1) and (2) into equation (3), yielding:

$\ln \left(\frac{1-R_{o b s}}{R_{o b s}}\right)=\frac{J_{v}}{k}+\ln \left(\frac{1-R_{\text {real }}}{R_{\text {real }}}\right)$

In this case, the mass transfer coefficient may be represented as

$k=a \omega^{n}$

where $\mathrm{a}$ and $\mathrm{n}$ are constants and $\omega$ is the stirrer speed. This approach to mass transfer (known as the infinite rejection method) is now widely adopted and is reported in many studies due to the inherent simplicity of the method and does not consider the effects of suction. The approach to mass transfer in frontal filtration is equally applicable to cross flow filtration by 
substitution of $\omega$ in equation (6) with velocity or volumetric flow rate through the membrane module, i.e. $k=a u^{n}$ or $k=a Q^{n}$. Essentially, in cross-flow mode, exactly the same membrane is used so the rejection performance will be identical. Any differences that do arise by changing format from frontal to cross-flow mode will be purely related to the change in mass transfer effects related to mixing quality at the membrane surface.

This result is applicable for uncharged solutes, but the correlation for a multi-component electrolyte system requires the solution of the extended Nernst-Planck equation [21]. The exponential term in equation (3) is known as the polarisation modulus and is a dimensionless term representing the extent of mass transfer and shows that when $\mathrm{C}_{\mathrm{w}}=\mathrm{C}_{\mathrm{f}}$ the modulus becomes unity and when concentration polarisation is occurring the modulus increases in magnitude. Thus, the polarisation modulus offers a simplistic quantitative comparison of mass transfer effects in different equipment. Many mass transfer correlations have been derived to predict $\mathrm{k}$ for simple membrane modules such as tubular and hollow-fibre membranes [22], frontal filtration equipment [23] and various other membrane geometries [24-27]. These correlations relate the dimensionless Sherwood number to Reynolds number and Schmidt number, i.e.:

$N_{S h}=\frac{k r}{D_{e f f, \infty}}=\varphi\left(N_{\mathrm{Re}}\right)^{n}\left(N_{S c}\right)^{0.33}$

where

$N_{\mathrm{Re}}=\frac{\omega r^{2}}{v}, N_{S c}=\frac{v}{D_{e f f, \infty}}$ and $\varphi$ is a constant.

For example the most suitable value for the empirical constant $n$ was found to be $0.567[23,28]$ in the Amicon cell. Bowen and Mukhtar [29] and Bowen et al. [30] used this correlation to account for concentration polarisation in the characterisation of nanofiltration membranes, namely

$k=0.23\left(\frac{r^{2}}{v}\right)^{0.567}\left(\frac{v}{D_{e f f, \infty}}\right)^{0.33} \frac{D_{e f f, \infty}}{r} \omega^{0.567}$

The estimation of mass transfer using accurate correlations allows accurate prediction of membrane separation performance, however, van der Berg et al. [31] highlighted the pitfalls in blindly using correlations and recommended the evaluation of the exponent $n$ from experimental data. Experimentally, the real rejection may be determined from the observed rejection on extrapolation to infinite stirrer speed by plotting $\ln \left[\left(1-R_{o b s}\right) / R_{o b s}\right]$ against $J_{v} / \omega^{n}$. The slope of the best fit line will be equal to $1 / a$. The real rejection may then be calculated by rearranging Eq. (5) to yield:

$$
R_{\text {real }}=\frac{1}{\operatorname{Exp}\left(\ln \left[\frac{1-R_{o b s}}{R_{o b s}}\right]-\frac{J v}{a \omega^{n}}\right)+1}
$$

The value of $R$ obtained is the real rejection at infinite stirrer speed.

\section{Membranes and Equipment Set Up}

Three commercially available frontal filtration membrane cells were obtained in order to conduct the experimental investigation. These were the Amicon 8050 (Merck Millipore UK Ltd., Watford, UK), the Sterlitech HP4750 (Sterlitech Corporation, Washington, USA) and the Membranology HP350 (Membranology Ltd., Swansea, UK). The operational limiting pressure is 5.17 bar, 69 bar and 100 bar for the Amicon, Sterlitech and Membranology cells respectively. Similarly, the operational membrane area is 13.4 $\mathrm{cm}^{2}, 14.6 \mathrm{~cm}^{2}$ and $41.8 \mathrm{~cm}^{2}$ and volume is $50 \mathrm{~mL}, 300$ $\mathrm{mL}$ and $350 \mathrm{~mL}$ respectively.

The Nadir UH004 membrane (Microdyn Nadir, Germany) was used for the investigation which has a reported molecular weight cut off (MWCO) of $4000 \mathrm{Da}$. The manufacturer's recommended operating region for this membrane is $\mathrm{pH} 0$ to 14,5 to $95^{\circ} \mathrm{C}$ and no maximum pressure. Membranes were cut to size for the three cells and was immersed overnight in ultrapure water in darkness at $3^{\circ} \mathrm{C}$.

Characterisation using a single sized solute has been shown to be more accurate than the filtration of mixtures [32] and so the solute used for this study was PEG 3400 (Sigma Aldrich, Dorset, UK) with a feed concentration of $600 \mathrm{mg} / \mathrm{L}$. Ultra pure reverse osmosis water was obtained from an Elix $3 \AA$ Essential water purification system (Merck Millipore UK Ltd., Watford, UK). All experiments were conducted in frontal filtration mode, as illustrated in Figure 1.

\section{Operating Conditions}

The Amicon cell was operated at 1, 3 and 5 bar with a stirrer speed of $0,60,120,180,240$ and $300 \mathrm{rpm}$; note that the maximum operating pressure for the 


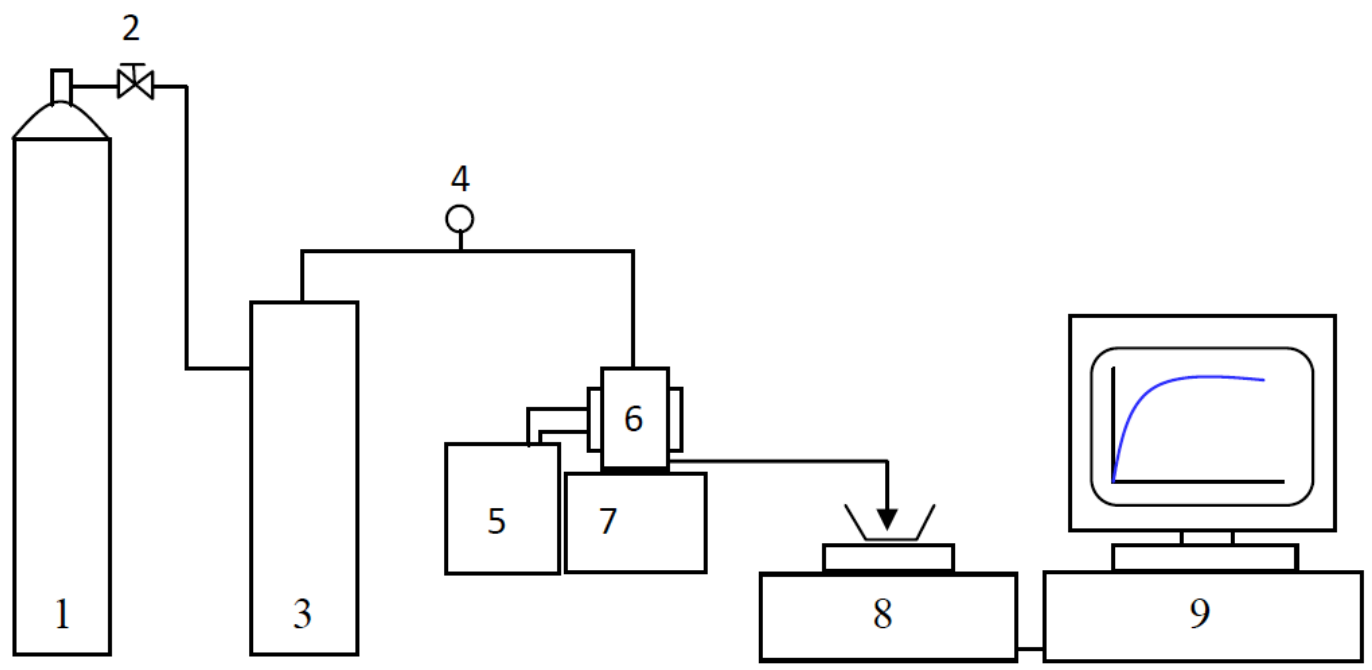

Figure 1: A schematic diagram of the frontal filtration equipment. (1) nitrogen cylinder, (2) valve, (3) feed reservoir, (4) pressure sensor, (5) water bath, (6) membrane cell, (7) magnetic stirrer, (8) electronic balance, (9) PC.

Amicon cell is 5.17 bar. The Sterlitech and Membranology cells were operated at 5, 10,20 and 30 bar with stirrer speeds of $0,60,120,180,240$ and 300 rpm.

Prior to starting experimentation, membranes were pressurised for $1 \mathrm{hr}$ at 5 bar with ultra-pure water for all three cells. The applied pressure for each of the cells was adjusted via a regulator connected to oxygen free nitrogen supply (BOC, UK), and monitored using a pressure sensor (Druck DPI 104, RS Components, UK) attached to the membrane cell. All membrane experiments were carried out at $25^{\circ} \mathrm{C}$, maintained by a water bath. Permeate flow was measured via the mass output of the cell monitored by an electronic balance (Ohaus Navigator N24120, Ohaus Europe, Switzerland) and recorded by a PC using WinWedge software (TAL Technologies, Pennsylvania), taking readings at 15 second intervals. The first $10 \mathrm{~mL}$ of permeate obtained was sent to waste in order to account for equipment hold up followed by the collection of a $10 \mathrm{~mL}$ permeate sample for analysis (due to the smaller operating volume of the Amicon cell only $2 \mathrm{~mL}$ was sent to waste and $3 \mathrm{~mL}$ was collected as a sample). This ensured that the cell contents variation over the duration of the experiment varied no more than $10 \%$ and this variation was neglected from calculations. Each experiment was conducted at least three times and the average result reported.

Sample analysis of PEG 3400 was carried out using a Varian Prostar 350 Refractive Index Detector (Agilent Technologies, Wokingham, UK). The PEG solutions were pumped through the detector using an Agilent 1100 (Agilent Technologies, UK) HPLC Pump and the signal generated was recorded. This signal value was then converted to the permeate PEG concentration by comparison to a calibration curve of known concentration.

\section{RESULTS AND DISCUSSION}

The effect of concentration polarisation is known to increase with increasing membrane flux and dissolved solute concentration [33]. Figure 2 shows the observed rejection plotted against membrane cell stirrer speed for various pressures for all three cells. Each data set shows a distinct variation between the three cells studied. The Amicon cell shows fairly consistent observed rejections of between 80 and $90 \%$, over the entire range of stirrer speeds, although at the highest stirrer speed $(350 \mathrm{rpm})$ the rejection falls to $50 \%$. Therefore the maximum practical stirrer speed for the Amicon cell was $300 \mathrm{rpm}$, above this speed the stirrer begins to rotate in a non-uniform manner and the motion is no longer smooth. This change in stirrer motion effectively reduces the mixing quality at the membrane surface and the membrane surface concentration increases as a result, i.e. concentration polarisation increases. In addition, the observed rejection for the Amicon cell is seen to be independent of pressure over the experimental range studied. The relationship between rejection and stirred speed shows greater variation in the data for the Sterlitech and Membranology cells when compared to the Amcion cell. Generally, in both the Sterlitech and Membranology cells observed rejection decreases with increasing pressure indicating the development of a concentration polarisation layer at the membrane surface with increasing flux. Stirrer speed has a greater 
effect on rejection in both the Sterlitech and Membranology cells when compared with the Amicon cell, with observed rejection increasing with increasing stirrer speed. The highest observed rejection for the Sterlitech cell was seen at $31.4 \mathrm{rad} / \mathrm{s}(300 \mathrm{rpm})$, with a rejection of $62 \%$ at 5 bar, decreasing to $8 \%$ at 30 bar. The Membranology cell exhibited a similar relationship as the Sterlitech cell but in this case the maximum rejection was $97 \%$ observed at $31.4 \mathrm{rad} / \mathrm{s}(300 \mathrm{rpm})$ at 5 bar and a minimum rejection of $18 \%$ at 30 bar. The reasoning behind the large differences in observed rejection is attributed in both cases to the build-up of a concentration polarisation layer at the membrane surface as a result of the increased flux associated with increased pressure. However, the Sterlitech cell exhibited a lower observed rejection at similar conditions when compared to the Membranology cell, suggesting that the larger more efficient stirrer in the Membranology cell helps minimize mass transfer effects. Furthermore, the Sterlitech cell stirrer is suspended at a greater height above the membrane surface instantly allowing the wall concentration to be greater than that of the feed. The stirrer mechanisms are shown in Figure 3; the three stirrers are suspended above the membrane surface. The assembly of the Amicon and Sterlitech cells are documented in the manufacturers' operating manuals $[34,35]$, whereas the Membranology cell is similar to the Amicon cell. The Amicon and Membranology cells have similar geometry consisting of a sweeping stirrer bar with only a slightly smaller dimension than the width of the stirred cell and is located only 1 to $2 \mathrm{~mm}$ above the membrane surface. This 'tight' geometry ensures that the maximum amount of stirring at the membrane surface is available. Furthermore, this geometry allows the stirrer to sweep the membrane surface and 'remove' the feed molecules from the membrane wall back to the bulk feed promoting thorough mixing. The Sterlitech cell uses a circular stirrer significantly smaller than that of the cell diameter and sits approximately $6 \mathrm{~mm}$ above the membrane surface; therefore, the membrane cell mixing properties are not as favourable as the mixing observed in the Membranology and Amicon cells. The Amicon cell is operated at pressures at or below 5 bar due to cell material limitations and the resulting maximum flux is much lower than the other two cells. Additionally the effective membrane area is smallest in the Amicon cell closely followed by the Sterlitech cell, with the largest membrane area belonging to the Membranology cell. This explains the fact that the Amicon cell observed rejection is very similar (in the range 70 to $90 \%$ ) across the pressure range studied as the flux is generally low $(1.726 \mathrm{ml} / \mathrm{min}$ at 5 bar, for pure water). Greater variation in observed rejection is noted for both the Sterlitech $(1.684 \mathrm{ml} / \mathrm{min}$ at 5 bar, pure water) and Membranology $(4.154 \mathrm{ml} / \mathrm{min}$ at $5 \mathrm{bar}$, for pure water) cells for similar operating conditions. This is a direct result of the increased flux of the Membranology cell as the membrane area is larger, i.e. there will be higher flux rate for the same applied pressure.
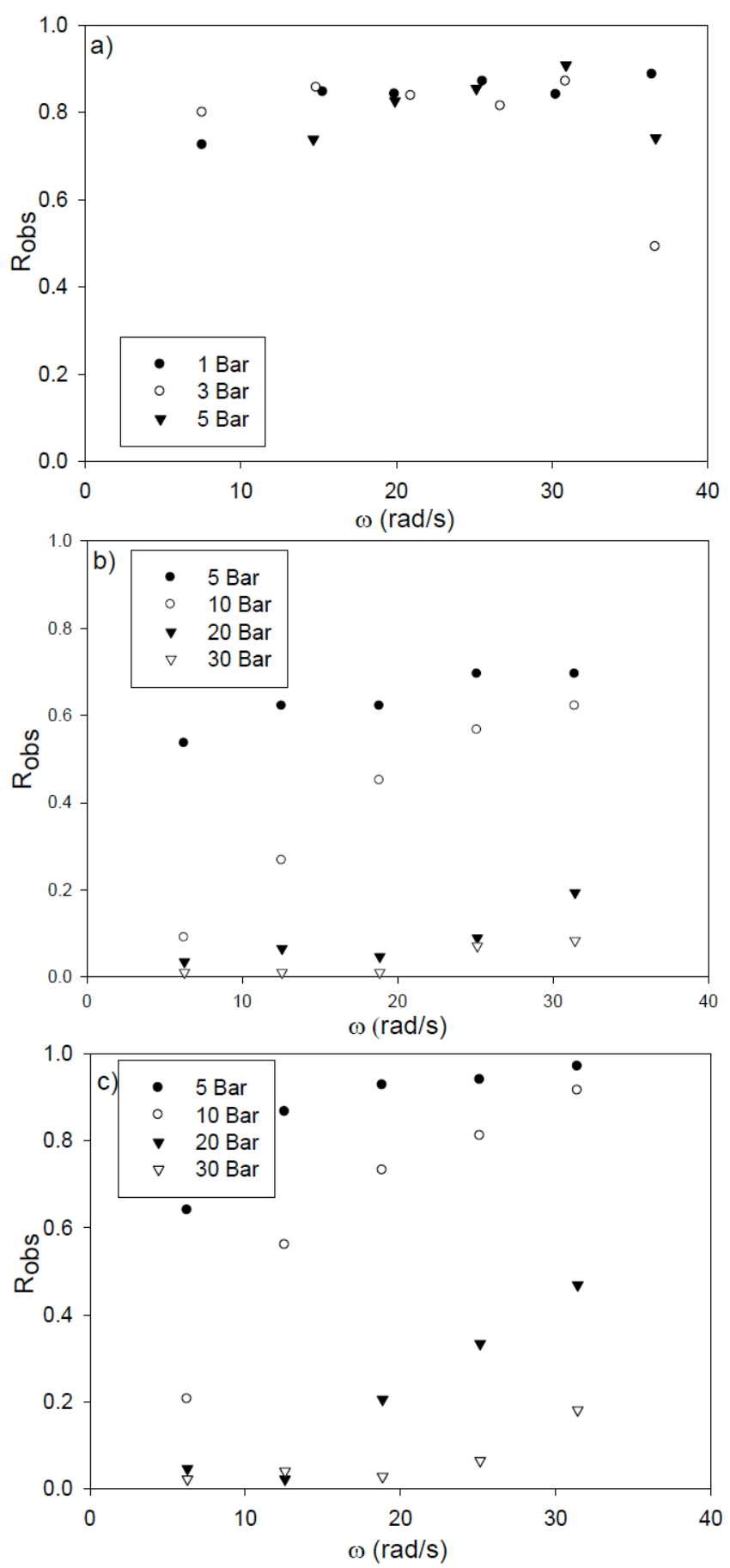

Figure 2: Observed rejection versus stirrer speed for a) Amicon cell, b) Sterlitech cell, c) Membranology cell. 


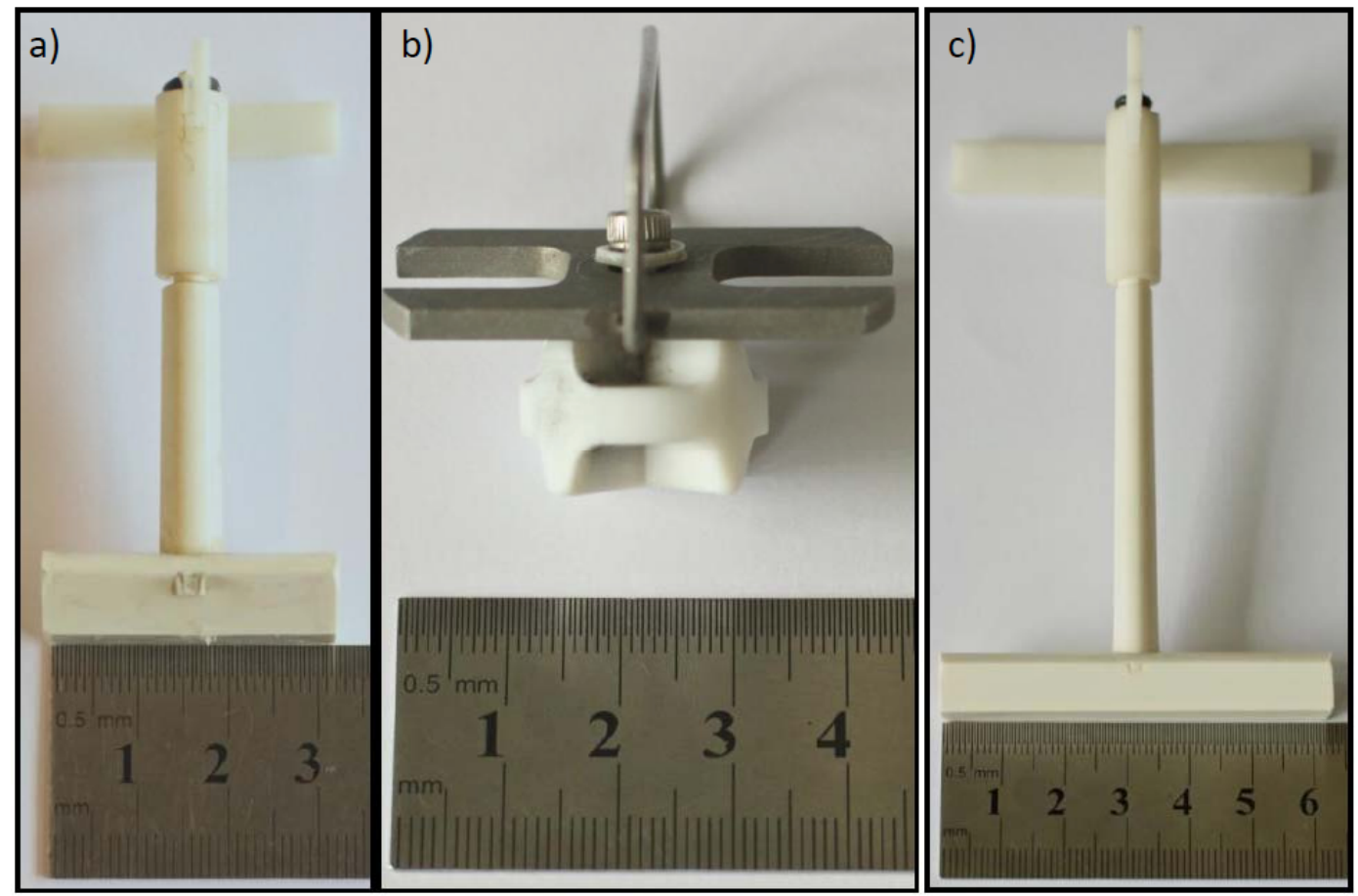

Figure 3: The stirrer configuration for the a) Amicon, b) Sterlitech, and c) Membranology stirred cell.

Figure 4 displays the observed and calculated real rejection against applied pressure for all three frontal filtration cells studied. Regardless of stirrer speed the general trend shows $R_{\mathrm{obs}}$ decreasing with increasing pressure for both the Membranology and Sterlitech cells, however, this effect is not seen in the Amicon cell and this observation is attributed to the low pressure used and the excellent mixing characteristics of the cell resulting in very little concentration polarisation. Note that when the stirrer speed in the Amicon cell exceeds $300 \mathrm{rpm}$ the data becomes anomalous, demonstrating that the stirrer is no longer functioning correctly as previously seen. The real rejection, $R_{\text {real }}$, generally remains constant across each of the cells and is in the region of 80 to $100 \%$, illustrating that the effects of the stirrer speed have now been removed. The scatter of the data is more evident with the Amicon and Sterlitech cells, with the Membranology cell providing almost consistent data at every stirrer speed and pressure. This could be attributed to the fact that the Membranology cell is the largest of the three cells studied and thus the data collected is more consistent due to reduced experimental error. The real rejection for the Amicon cell is very comparable to the observed rejection, with a greatest difference of $9.4 \%$ observed at $5 \mathrm{Bar}$ and $360 \mathrm{rpm}$ (a stirrer speed which has previously been noted as unreliable). The average difference between observed and real rejection for the Amicon cell was $0.2 \%$, i.e. the values are the same if one accounts for experimental error. This suggests that there is very little, if any, concentration polarisation occurring in the Amicon cell and the mass transfer effect is negligible. This result is similar to a previous study by Bowen et al. [36] who reported a difference of $3.7 \%$ between real and observed rejection in an Amicon 8400 (400 mL capacity) stirred cell. The real rejection for the Sterlitech and Membranology cells differ greatly when compared with the observed rejection and the average difference between the observed and real rejection is 68.4 and $45.6 \%$ respectively. This indicates that significant concentration polarisation is occurring in each of these cells. The greatest difference between observed and real rejection was at the highest pressures with lowest stirrer speeds as would be expected. Previous experimental work carried out by Nguyen et al. [24] and Bowen et al. [30] used maximum applied pressures of 1.2 and 5 bar respectively. In these two studies, and similarly for the Amicon cell in this study, there was very little mass transfer occurring. However, this study with the Sterlitech and Membranology cells show that as pressure increases, the flux rate increases and the resulting mass transfer is governed by convective transport of solute to the membrane surface. This convective flux to the membrane surface is significantly higher than the mixing rate removing solute from the membrane surface and thus concentration polarisation is inevitable. Thus, if a membranologist was to conduct feasibility studies in each of these three cells for potential new applications, then the results obtained 

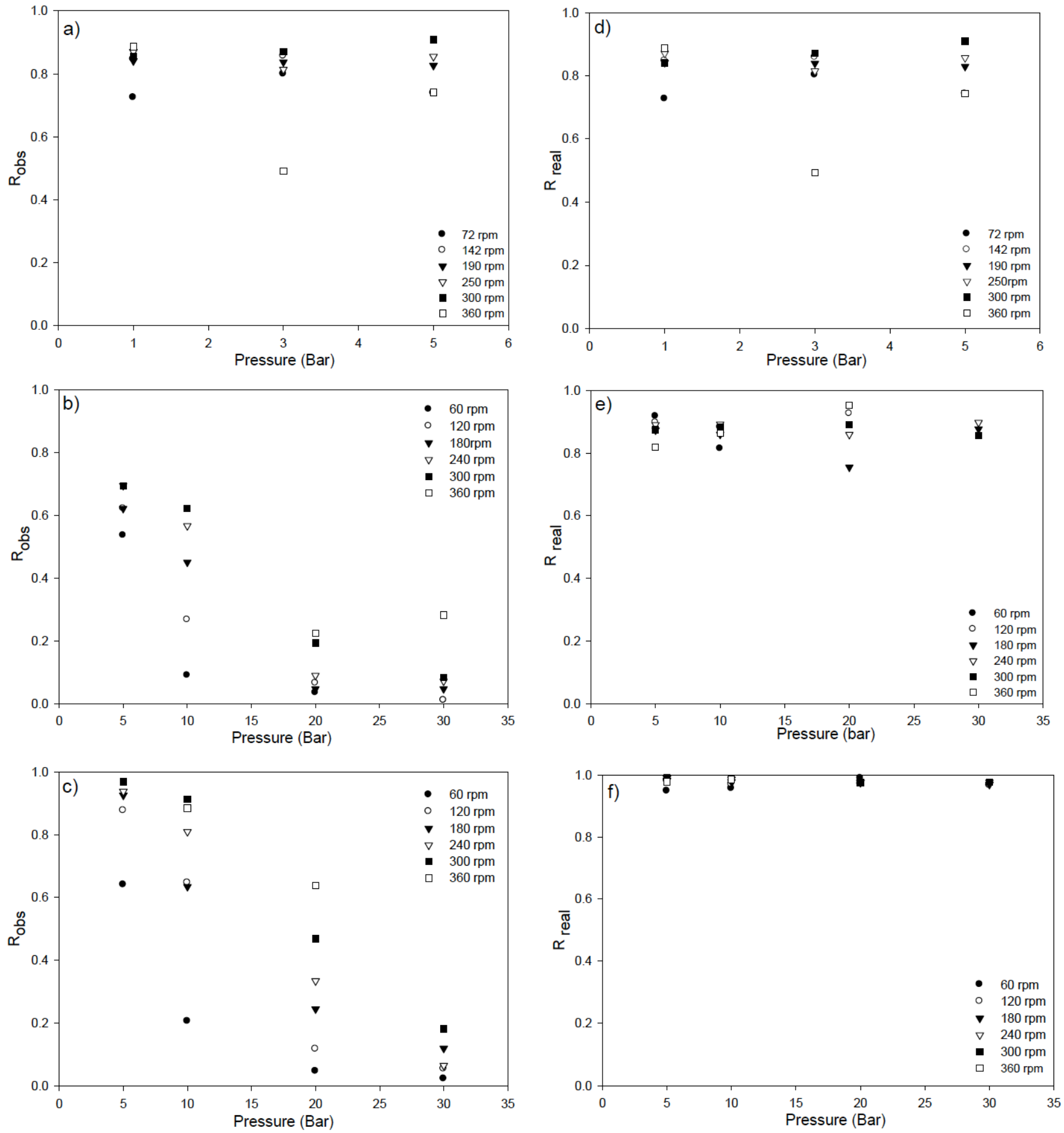

Figure 4: Observed rejection versus pressure for a) Amicon cell, b) Sterlitech cell, c) Membranology cell and real rejection versus pressure for d) Amicon cell, e) Sterlitech cell, f) Membranology cell.

would show an unfavourable process if the Sterlitech or Membranology cell was used without a knowledge of this mass transfer effect. This is clearly illustrated by considering the case of $60 \mathrm{rpm}$ at 30 bar for the Membranology cell where the observed rejection is $<5$ $\%$, i.e. no feasible separation process, and the real rejection is > $95 \%$, which would be considered to be an excellent separation.
An experimental observation made for all three cells is that as the stirrer speed increases (especially as the feed level decreases) vortexing is induced within the cells. When the vortexing is significant, the cone can extend from the top of the feed liquid to the membrane surface creating a smaller observed membrane active area. In this study this effect was reduced as much as possible by operating at the maximum cell volume. 
Furthermore, concentration polarisation and mass transfer descriptions are inaccurate when significant vortexing occurs. The experimental work undertaken in this paper would suggest that the optimum stirrer speed to use in the Amicon cell would be $300 \mathrm{rpm}$. A previous study that developed mass transfer correlations for the Amicon cell has reported using stirrer speeds up to $1300 \mathrm{rpm}$ [23]. This high stirrer speed could not be obtained in this study using similar equipment (the stirrer simply would not turn in the magnetic field) and with the observation of vortexing this would question the validity of the data produced. A general recommendation from this work would be to investigate improved mixing strategies to avoid vortexing in frontal filtration cells which should reduce concentration polarisation and minimise fouling.

The mass transfer coefficient was calculated using the infinite rejection method, see Eq (5). The three data sets obtained as Figure $\mathbf{4}$ were further manipulated and plotted in the form $\ln \left[\left(1-R_{o b s}\right) / R_{o b s}\right]$ against $J_{V} / \omega^{n}$ and are shown in Figure 5. The value for the exponent $n$ for each cell was determined by optimisation of the coefficient of determination $\left(\mathrm{R}^{2}\right)$. The $n$ and $a$ values obtained from the experimental data are shown in Table 1. Figure 5 facilitates the comparison of the mass transfer effect within each of the three cells by comparison of the gradients of the best fit line, the greater the gradient the higher the mass transfer effect. The Amicon cell displayed a shallow positive gradient and therefore confirms that the Amicon cell has very little mass transfer occurring due to the low flux and high quality of mixing. This justifies the statement that the observed rejection is independent of the applied pressure across the experimental range studied as the observed rejection is in fact very similar to the real rejection as a result of the minimal mass transfer occurring. The Sterlitech and Membranology cells display a gradient of approximately $45^{\circ}$, suggesting the difference between observed and real rejection is increasing as the $J_{v} / \omega^{n}$ term increases. As the gradient is similar for both cells, this indicates that the mass transfer effect is also similar in both cells and much greater than that of the Amicon cell. However, the flux rate obtained in the Membranology cell was far superior when compared to the Sterlitech cell due to the larger membrane area. This indicates that the true mass transfer effect is less in the Membranology cell when compared to the Sterlitech cell as a result of the better mixing rates generated by the superior stirrer design. The large range of extrapolated values of $R$ on the $y$-axis can be explained by the varying cell observed rejections. The observed rejection versus pressures for the Sterlitech and Membranology cells display an observed rejection ranging from 10 to $90 \%$ which explains the large data spread in Figure $\mathbf{5}$ for the Sterlitech and Membranology cells.

Table 1: Mass Transfer Constants for the Three Frontal Filtration Cells Studied

\begin{tabular}{|c|c|c|}
\hline & $\mathbf{a}$ & $\mathbf{n}$ \\
\hline \hline Amicon & $1.080 \mathrm{E}-05$ & 0.567 \\
\hline Sterlitech & $2.771 \mathrm{E}-06$ & 0.487 \\
\hline Membranology & $2.993 \mathrm{E}-06$ & 0.415 \\
\hline
\end{tabular}

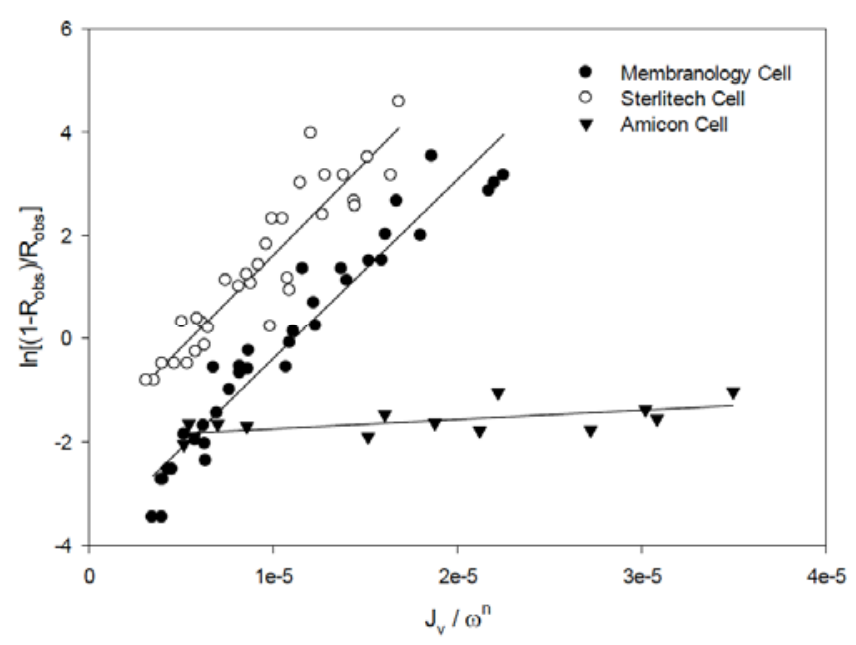

Figure 5: Linear analysis to determine the mass transfer coefficients of the Membranology, Sterlitech and Amicon frontal filtration cells.

The calculated mass transfer coefficient (Eq. (5)) from this study was compared to the mass transfer coefficient obtained from the correlation (Eq. (9)) first proposed by Nakao and Kimura [20] and used by Bowen et al. [30] using the updated mass transfer constants derived in this study (Table 1) and is shown in Figure 6. The correlation greatly under exaggerated the mass transfer effect within the cells when compared with the experimental data obtained in this study. For example, the Amicon data (Figure 6a) gives an experimental mass transfer coefficient of $\sim 3.4 \times 10^{-}$ ${ }^{5} \mathrm{~m} \mathrm{~s}^{-1}$ which corresponds to a theoretical value of $\sim 2.8 \times 10^{-6} \mathrm{~m} \mathrm{~s}^{-1}$, which is a significant underestimation. The correlation in question was developed for UF membranes, however, the membrane used in this study is representative of a very tight UF or loose NF and this may explain the discrepancy observed.

The polarisation modulus was calculated from the experimental data and is shown in Figure 7. The 

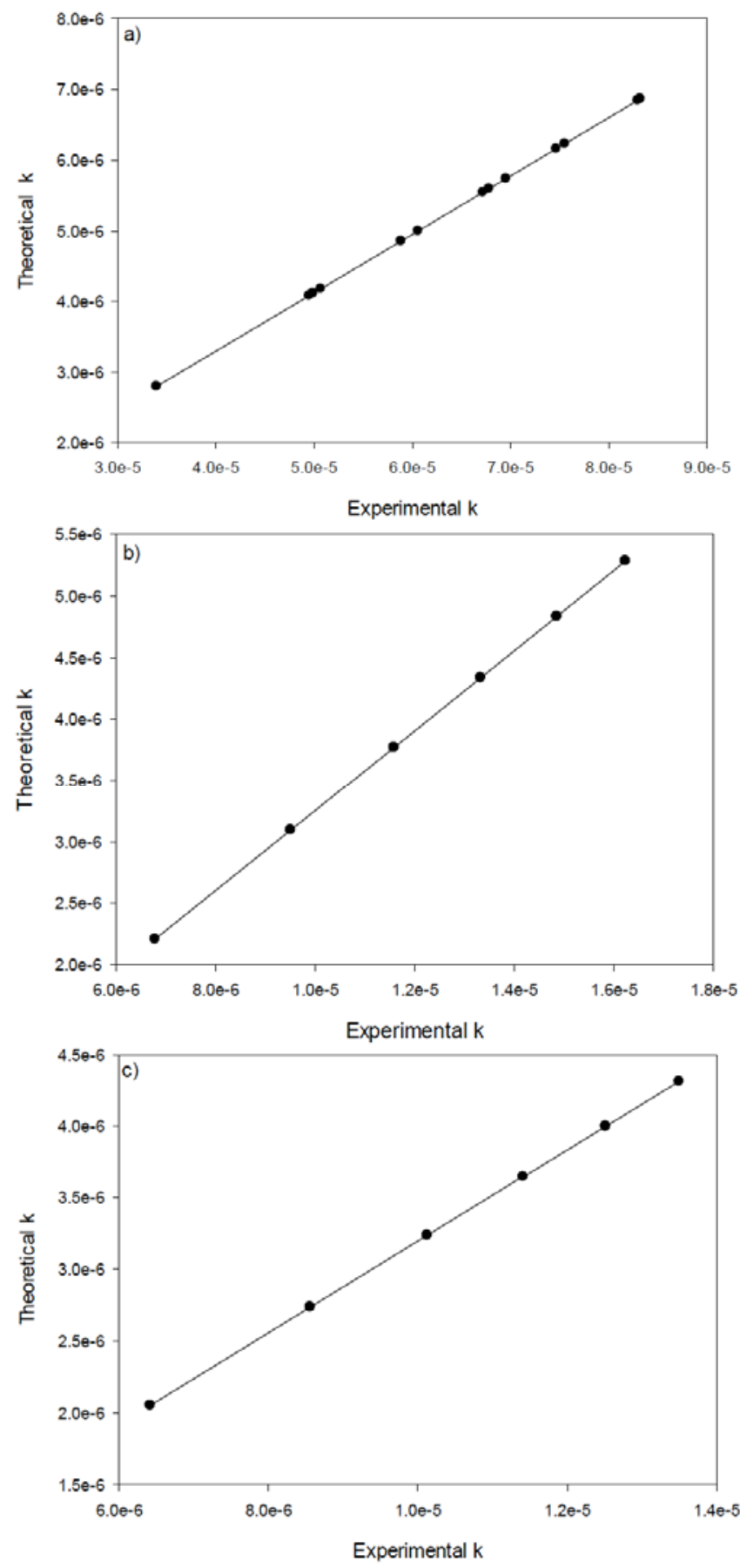

Figure 6: Comparison between experimental and theoretical mass transfer coefficient for the a) Amicon, b) Sterlitech, and c) Membranology stirred cell.

previous correlation [30] is plotted as a reference guide and the Amicon data is seen to lie just outside of the correlation (abscissa region 1 to 10) as expected. However, in this case, the rest of the data points also deviate significantly from the correlation data. This is potentially due to the fact that the flux is an order of magnitude greater than the mass transfer coefficient and the resulting polarisation modulus is very large. For example, at a flux of $63 \times 10^{-6} \mathrm{~ms}^{-1}$ and $300 \mathrm{rpm}$ for the
Sterlitech and Membranology cells, the correlation predicted a polarisation modulus of $6.4 \times 10^{5}$ and $8.3 \times 10^{8}$ respectively. These two values are ridiculously large and the experimental data obtained for the Sterlitech and Membranology cells respectively gave a polarisation modulus of 77.5 and 162.6 at similar conditions. The theoretical data obtained for the Amicon cell was larger than that of the experimental (theoretical polarisation modulus of 31.4 at a flux of 21 $\times 10^{-6} \mathrm{~m} \mathrm{~s}^{-1}$ at $300 \mathrm{rpm}$ and a experimental polarisation modulus of 1.3 for the same conditions), however, this difference was insignificant when compared to the error in the Sterlitech and Membranology cells. As stated previously, the theoretical correlations relate to UF membranes where the pressure applied is small. However, for NF membranes the pressure used is much higher to obtain high flux rates. The data in Figure 7 would suggest that the concentration polarisation follows similar behaviour to that of UF membranes but is off-set by an order of magnitude. This is a similar observation to that seen previously using the NF270 membrane in cross flow mode [33]. To account for this off-set, a dimensionless term was added to Eq. (7) and is given as:

$\left(1+\left(\frac{J_{v}}{\omega r}\right)^{x}\right)$

where $x$ is an empirical coefficient. The expression provided in Eq. (11) is simply a modification factor in dimensionless format that will increase in magnitude as the flux increases, i.e. this will account for the deviation from the current correlation that is seen at increased flux levels. Also, when the flux is small, the modification term will tend to unity and will be negligible. Therefore, manipulating Eq. (7), the equation used to predict the mass transfer effect now becomes:

$N_{S h}=\varphi\left(N_{R e}\right)^{n}\left(N_{S c}\right)^{0.33}\left(1+\left(\frac{J v}{\omega r}\right)^{x}\right)$

The additional term will account for the off-set in the polarisation modulus seen at high flux rates for this membrane and when the flux rate is low then the additional term will become negligible and the correlation will revert back to Eq. (7). Introduction of this correction factor resulted in the mass transfer coefficient for each of the cells being calculated as a much higher value and the resulting polarisation modulus being more comparable to that observed experimentally, as can be seen in Figure 7 . 


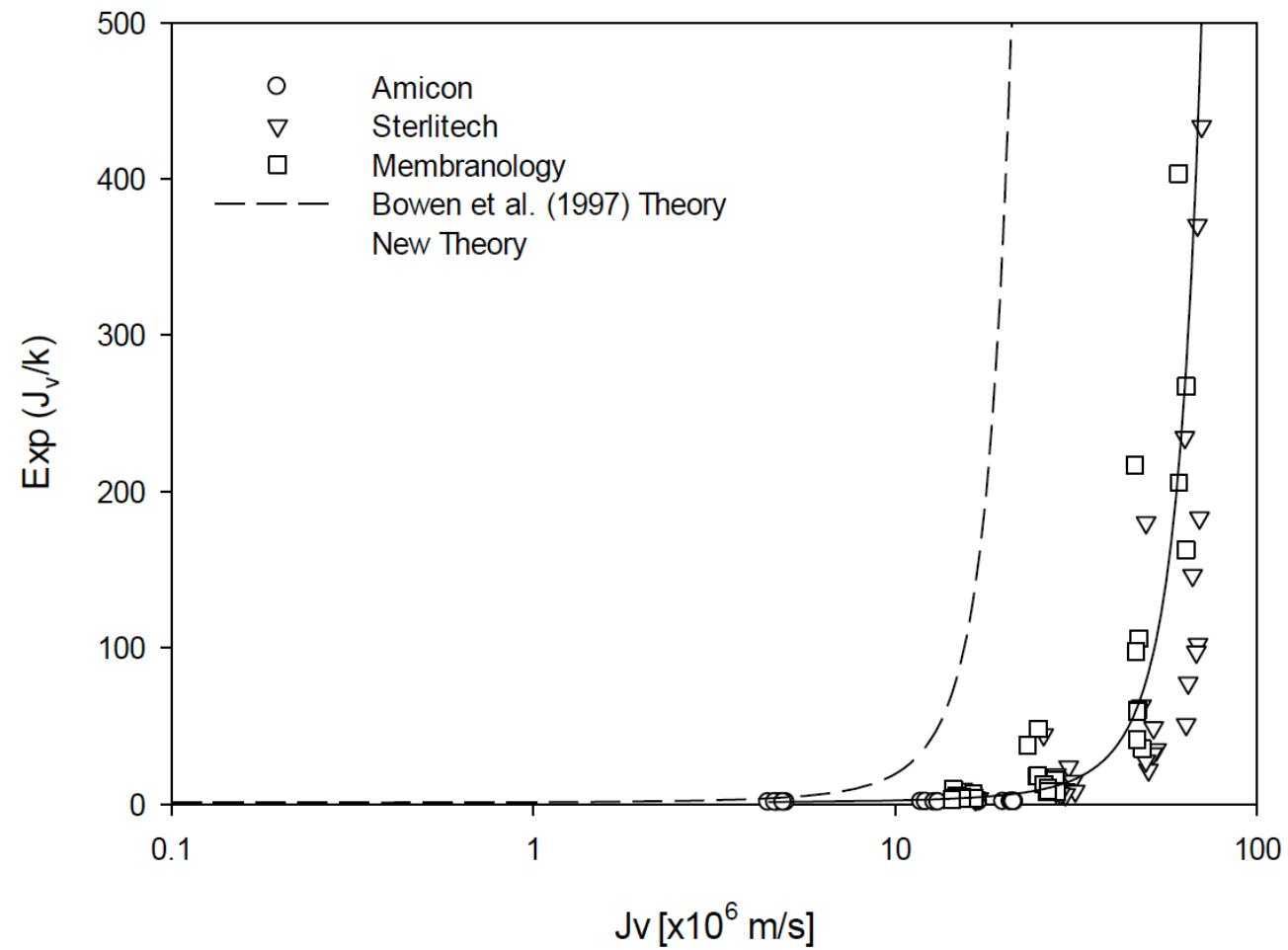

Figure 7: Comparison of calculated mass transfer effect using the Bowen et al. [30] correlation to that of the proposed correlation.

\section{CONCLUSION}

A mass transfer study has been conducted using three commercially available laboratory frontal filtration membrane cells using PEG 3400 and a 4000 MWCO membrane. The Amicon cell was used as this equipment has been widely implemented for laboratory UF membrane studies. However, the cell is largely impractical for NF applications due to the 5 bar maximum operating pressure and should be considered only suitable for MF and UF applications. Both the Sterlitech and Membranology cells used in this study are high pressure cells and are suitable for NF applications. This work has demonstrated that a maximum stirrer speed of approximately $300 \mathrm{rpm}$ is suitable for most applications using each of the membrane cells studied. Concentration polarisation was not observed, or was very minimal, when using the Amicon cell and this was attributed to the low flux rates obtained as a result of the low pressure operation. However, the increased flux rates generated in the Sterlitech and Membranology cells as a result of the higher operating pressure used developed a significant concentration polarisation layer leading to disparity between observed and real rejection (a very important concept when considering process scale up). The mass transfer effect observed in the high pressure cells was similar, however, due to the Membranology cell having a larger membrane area the cell showed better flux performance and was superior when compared to the Sterlitech cell, i.e. the same mass transfer effect at an increased flux rate.

The experimental mass transfer results obtained were compared with the accepted theoretical descriptions and the correlation was found to significantly under-estimate the magnitude of the mass transfer coefficient for the membrane and equipment used. The theory was then modified to include a correction factor to account for the high pressure (and relative flux) and larger mass transfer effect observed with NF membranes. This correction factor facilitated a more accurate prediction of the polarisation modulus and was accepted as a reasonable description of the interfacial phenomena occurring. This work suggests that this new theoretical mass transfer correlation is more appropriate for NF and tight UF membranes in frontal filtration mode. This work demonstrates that blindly using mass transfer correlations developed for UF applications can lead to significant errors when considering NF applications. More work is required with different NF membranes to further support the correlation developed.

Having successfully determined the mass transfer effects within these three commercially available frontal 
filtration cells, the prudent scientist or engineer can now use this information for increased process understanding during the evaluation and scale-up of new membrane processes.

\section{ACKNOWLEDGEMENT}

This work is part-funded by the European Social Fund (ESF) through the European Union's Convergence programme administered by the Welsh Government and EnAlgae.

\section{NOMENCLATURE}

$$
\begin{array}{ll}
\mathrm{R}_{\mathrm{obs}} & =\text { Membrane observed rejection } \\
\mathrm{R}_{\text {real }} & =\text { Real membrane rejection } \\
\mathrm{C}_{\mathrm{p}} & =\text { Permeate concentration } \\
\mathrm{C}_{\mathrm{F}} & =\text { Feed concentration } \\
\mathrm{C}_{\mathrm{w}} & =\text { Membrane wall concentration } \\
\mathrm{J}_{\mathrm{v}} & =\text { Membrane Flux (m/s) } \\
\mathrm{k} & =\text { Mass transfer coefficient (m/s) } \\
D_{\text {eff }}, & =\text { Effective diffusion coefficient }\left(\mathrm{m}^{2} / \mathrm{s}\right) \\
\delta & =\text { Thickness of concentration polarisation layer } \\
\mathrm{\omega} & =\text { Stirrer speed (rad } / \mathrm{s}) \\
\mathrm{a} & =\text { Constant } \\
\mathrm{n} & =\text { Constant } \\
\mathrm{r} & =\text { Cell radius }(\mathrm{m}) \\
\mathrm{v} & =\text { Kinematic viscosity }(\text { Pa/s) }
\end{array}
$$

\section{REFERENCES}

[1] Wang R, Li Y, Wang J, You G, Cai C, Chen BH. Modeling the permeate flux and rejection of nanofiltration membrane separation with high concentration uncharged aqueous solutions. Desalination 2012; 299: 44-49. http://dx.doi.org/10.1016/j.desal.2012.05.014

[2] Bhattacharjee C, Datta S. Analysis of polarized layer resistance during ultrafiltration of PEG-6000: an approach based on filtration theory. Separation and Purification Technology 2003; 33: 115-126. http://dx.doi.org/10.1016/S1383-5866(02)00142-9

[3] Wyart Y, Georges G, Deumie C, Amra C, Moulin P. Membrane characterization by microscopic methods: Multiscale structure. Journal of Membrane Science 2008; 315: 82-92. http://dx.doi.org/10.1016/j.memsci.2008.02.010

[4] Ball P. Scale-up and scale-down of membrane-based separation processes. Membrane Technology 2000; 117: 1013.

http://dx.doi.org/10.1016/S0958-2118(00)86634-3
[5] Maskan F, Wiley DE, Johnston LPM, Clements DJ. Optimal design of reverse osmosis module networks. AIChE Journal 2000; 46: 946-954.

http://dx.doi.org/10.1002/aic.690460509

[6] Kawachale N, Kirpalani DM, Kumar A. A mass transport and hydrodynamic evaluation of membrane separation cell. Chemical Engineering and Processing: Process Intensification 2010; 49: 680-688. http://dx.doi.org/10.1016/i.cep.2009.08.001

[7] Koutsou CP, Karabelas AJ. Shear stresses and mass transfer at the base of a stirred filtration cell and corresponding conditions in narrow channels with spacers. Journal of Membrane Science 2012; 399-400: 60-72.

[8] Chen J, Li Q, Elimelech M. In situ monitoring techniques for concentration polarisation and fouling phenomena in membrane filtration. Advances in Colloid and Interface Science 2004; 107: 83-108. http://dx.doi.org/10.1016/i.cis.2003.10.018

[9] Guo W, Ngo H-H, Li J. A mini-review on membrane fouling. Bioresource Technology 2012; 122: 27-34. http://dx.doi.org/10.1016/j.biortech.2012.04.089

[10] Sablani SS, Goosen MFA, Al-Belushi R, Wilf M. Concentration polarization in ultrafiltration and reverse osmosis: a critical review. Desalination 2001; 141: 269-289. http://dx.doi.org/10.1016/S0011-9164(01)85005-0

[11] Ma S, Kassinos SC, Kassinos DF. Assessing the impact of concentration-dependent fluid properties on concentration polarization in crossflow membrane systems. Industrial \& Engineering Chemistry Research 2008; 47: 1636-1649. http://dx.doi.org/10.1021/ie0713893

[12] Kim S, Hoek EMV. Modelling concentration polarization in reverse osmosis processes. Desalination 2005; 186: 111128.

http://dx.doi.org/10.1016/j.desal.2005.05.017

[13] Sherwood TK, Brian PLT, Fisher RE, Dresner L. Salt Concentration at Phase Boundaries in Desalination by Reverse Osmosis. Industrial \& Engineering Chemistry Fundamentals 1965; 4: 113-118.

http://dx.doi.org/10.1021/i160014a001

[14] Mulder M. Basic Principles of Membrane Technology, 2nd Edition, Springer 1996. http://dx.doi.org/10.1007/978-94-009-1766-8

[15] Dresner L, Johnson JS. Hyperfiltration (Reverse Osmosis) in: Spiegler, K.S., and A.D.K. Laird, Principles of Desalination, 2nd edition, Academic Press 1980.

[16] Nagy E, Kulcsar E, Nagy A. Membrane mass transport by nanofiltration: Coupled effct of the polarization and membrane layers. Journal of Membrane Science 2011; 368: 215-222.

http://dx.doi.org/10.1016/j.memsci.2010.11.046

[17] Rohani R, Hyland M, Patterson D. A refined one-filtration method for aqueous based nanofiltration and ultrafiltration membrane molecular weight cut-off determination using polyethylene glycols. Journal of Membrane Science. 2011; 382: 278-290.

http://dx.doi.org/10.1016/j.memsci.2011.08.023

[18] Mohammad AW, Hilal N, Al-Zoubi H, Darwish NA. Prediction of permeate fluxes and rejections of highly concentrated salts in nanofiltration membranes. Journal of Membrane Science 2007; 289: 40-50.

http://dx.doi.org/10.1016/..memsci.2006.11.035

[19] Nicolas S, Balannec B, Beline F, Bariou B. Ultrafiltration and reverse osmosis of small non-charged molecules: a comparison study of rejection in a stirred and unstirred batch cell. Journal of Membrane Science 2000; 164: 141-155. http://dx.doi.org/10.1016/S0376-7388(99)00191-X

[20] Nakao S, Kimura S. Analysis of solutes rejection in ultrafiltration. Journal of Chemical Engineering of Japan 1981; 14: 32-37.

http://dx.doi.org/10.1252/jcej.14.32 
[21] Bowen WR, Mohammad AW. Diafiltration by nanofiltration: Prediction and optimization. AIChE Journal 1998; 44: 17991812. http://dx.doi.org/10.1002/aic.690440811

[22] Rautenbach R, Albrecht R. Membrane Processes, John Wiley, Chichester 1994.

[23] Opong WS, Zydney AL. Diffusive and convective protein transport through asymmetric membranes. AIChE Journal 1991; 37: 1497-1510. http://dx.doi.org/10.1002/aic.690371007

[24] Nguyen QT, Aptel P, Neel J. Characterization of UF membranes, Part II. Mass transport measurements for low and high molecular weight synthetic polymer in water solution. Journal of Membrane Science 1980; 7: 141-155. http://dx.doi.org/10.1016/S0376-7388(00)80078-2

[25] De S, Battacharya PK. Prediction of mass-transfer coefficient with suction in the applications of reverse osmosis and ultrafiltration. Journal of Membrane Science 1997; 128: 119131.

http://dx.doi.org/10.1016/S0376-7388(96)00313-4

[26] Minnikanti VS, DasGupta S, De S. Prediction of mass transfer coefficient with suction for turbulent flow in cross flow ultrafiltration. Journal of Membrane Science 1999; 157: 227239. http://dx.doi.org/10.1016/S0376-7388(98)00371-8

[27] Geraldes V, Dina-Afonso M. Generalized mass-transfer correction factor for nanofiltration and reverse osmosis. AIChE J 2006; 52: 3353-3362. http://dx.doi.org/10.1002/aic.10968

[28] Malone DM, Anderson JL. Diffusional boundary-layer resistance for membranes with low porosity. AIChE Journal 1977; 23: 177-184. http://dx.doi.org/10.1002/aic.690230206

[29] Bowen WR, Mukhtar H. Characterisation and prediction of separation performance of nanofiltration membranes. Journal of Membrane Science 1996; 112: 263-274. http://dx.doi.org/10.1016/0376-7388(95)00302-9
[30] Bowen WR, Mohammad AW, Hilal N. Characterisation of nanofiltration membranes for predictive purposes - use of salts, uncharged solutes and atomic force microscopy. Journal of Membrane Science 1997; 126: 91-105. http://dx.doi.org/10.1016/S0376-7388(96)00276-1

[31] van der Berg GB, Racz IG, Smolders CA. Mass transfer coefficients in cross-flow ultrafiltration. Journal of Membrane Science 1989; 47: 25-51. http://dx.doi.org/10.1016/S0376-7388(00)80858-3

[32] Causserand C, Rouaix S, Akbari A, Aimar P. Improvement of a method for the characterization of ultrafiltration membranes by measurements of tracers retention. Journal of Membrane Science 2004; 238: 177-190. http://dx.doi.org/10.1016/j.memsci.2004.04.003

[33] Oatley DL, Llenas L, Perez R, Williams PM, Martínez-Lladó $X$, Rovira M. Review of the dielectric properties of nanofiltration membranes and verification of the single oriented layer approximation. Advances in Colloid and Interface Science 2012; 173: 1-11. http://dx.doi.org/10.1016/j.cis.2012.02.001

[34] Millipore Corporation. Stirred Ultrafiltration Cells User Guide 2008, Available at: https://www.millipore.com/userguides.nsf/ a73664f9f981af8c852569b9005b4eee/e7e01888faba2f89852 574dc00818382/\$FILE/99228.pdf

[35] Sterlitech Corporation, HP4750 Stirred Cell Assembly and Operation Manual, Available at: https://www.sterlitech.com/ media/wysiwyg/pdfs/HP4750_Manual_V2013-Final.pdf

[36] Bowen WR, Cassey B, Jones P, Oatley DL. Modelling the performance of membrane nanofiltration - application to an industrially relevant separation. Journal of Membrane Science 2004; 242: 211-220. http://dx.doi.org/10.1016/j.memsci.2004.04.028

\section{DOI: http://dx.doi.org/10.6000/1929-6037.2015.04.04.1}

(C) 2015 Oatley-Radcliffe et al.; Licensee Lifescience Global.

This is an open access article licensed under the terms of the Creative Commons Attribution Non-Commercial License (http://creativecommons.org/licenses/by-nc/3.0/) which permits unrestricted, non-commercial use, distribution and reproduction in any medium, provided the work is properly cited. 